\title{
Romanian family business internationalization: knowledge management and dynamic capabilities
}

\author{
Adrian MOTOC \\ National University of Political Studies and Public Administration, Bucharest, Romania \\ adrian.motoc@facultateademanagement.ro
}

\begin{abstract}
The key aspects of today's economic climate are intensified competitiveness and fast-changing global markets. In order to stay competitive, family companies need to respond to these developments and more frequently seek foreign expansion themselves. To understand how organisations should respond to changes in the market to retain a competitive edge, the idea of knowledge management and dynamic capabilities has indeed been developed. Such an environmental transition could be the internationalisation of a family business. The purpose of this research is to examine, through the lens of knowledge management and dynamic capabilities, the internationalisation of family companies. A qualitative single case study model of a family business that has been through an international expansion has been considered, collecting evidence through semi-structured qualitative interviews with three of the company's key individuals. The study reveals that in the internationalisation process, there are many skills that assist family companies. Sensing technologies include screening capabilities for networks and industries and helping family companies identify new prospects in international markets. Seizing skills provide decision-making and management capabilities and change the capital base to take advantage of the possibilities previously sensed. Finally, family businesses should constantly reconfigure their tools with transforming skills, which consist of entrepreneurial knowledge capabilities, to optimise processes and frameworks in the current international setting. Different facets of family life influence the development of these complex skills.
\end{abstract}

Keywords: family business, internationalisation, knowledge management, dynamic capabilities.

\section{Introduction}

One of the 21st century's most influential megatrends is globalisation and the rising importance of foreign markets (Singh et al., 2009). To align with the current conditions, businesses need to respond to evolving environments and restructure their market strategy. Expanding their market abroad is one way for firms to tap the global economy. In general, internationalisation can be defined as a method of initiating, improving and sustaining international business relations (Johanson \& Mattsson, 1988). This mechanism has been widely researched, but mostly related to massive stock firms. However, for many small and medium-sized firms that are often embodied by family enterprises, penetration into foreign markets is still an essential factor for success and growth (D'Souza \& McDougall, 1989). A family business varies from most corporations because it is a business run and operated by members of the same family or a coalition of many families for the goal of creating income for future generations of these families (Chua et al., 1999). If the people who actually run the firm have either created or inherited it, a corporation is called a family company (Hoy \& Sharma, 2009). About 80 per cent of all companies worldwide are family businesses, also being considered the backbone of the world economy (Fernádez-Aráoz, 2015) since they have an economic effect of over 70 per cent of the global GDP. As an incentive to pursue new growth areas for strategic competitive advantage and as a way to tackle economic stagnation, family companies are now trying to internationalise. Internationalisation has always been an avenue for many family companies to extend their companies, but it has acquired more

DOI: $10.2478 /$ picbe-2021-0016

(C) 2021 A. Motoc, published by Sciendo.

This work is licensed under the Creative Commons Attribution 4.0 License. 
appeal in the literature with recent technology developments, intensified foreign competition and the prospect of economic growth (De Massis et al., 2017).

Family business internationalisation has primarily been examined with theories that concentrate on the interaction and motivational aspects of management and family, including the agency theory and stewardship theory (Avrichir et al., 2016). There are, however, other facets of the family that need attention in this sense. Any internationalisation process is a significant shift in the family business climate that leads to confusion and unforeseen challenges. The definition of complex capabilities by Teece (1997) was created to illustrate how it is possible to mitigate these uncertainties. There is current literature on knowledge management and dynamic capabilities and internationalization and on dynamic capabilities inside family businesses (Chirico \& Nordqvist, 2010, Barros, et al., 2016); however, the effect of a family business on the development of knowledge management and dynamic capabilities for family business internationalisation has not yet been examined. This paper aims to fill this void in the literature, exploring how family businesses adapt to internationalisation's environmental shift and what sort of skills they need to build in order to do so. As a useful prism through which to perform the analytical research, the micro-foundations of complex capacities, classified into sensing, seizing and transforming are used. There will be an emphasis on how the family business's individual aspects impact the creation of complex capabilities.

\section{Literature review}

In the work of Hymer, who wrote about global corporations in 1960, Knight and Liesch (2016) define the beginning of the international market analysis. Nevertheless, the most significant contribution to this analysis in the literature begins with Johanson and Wiedersheim-Paul, who began with the introduction of a stage model of internationalisation in 1975, which evolved into the well-known model of Uppsala internationalisation, followed by the work of Johanson and Vahlne (1977). The Uppsala model can be viewed as a model of a growing internationalisation process, with the most critical aspects being awareness and consumer participation (Johanson \& Vahlne, 1977). Other perspectives have arisen in scientific study, in addition to the detailed research on internationalisation from a stage model lens. Jones and Coviello (2005) conceptualise internationalisation as a long-term organisational behavioural phenomenon that is unique to the particular company and its interactions, continuing the line of analysis that forbids the classification of internationalisation phases. The network approach, which deals with network relationships that allow companies to internationalise, can also be listed. The issue of why businesses internationalise should be raised, moving away from the analytical lenses that have been applied to understand the internationalisation process. Oesterle et al. (2013) noted that by being involved in various countries, the most critical factors for businesses to internationalise are, among others, business motives, more excellent operating stability, corporate learning or risk diversification. Export searching and seeking reduced transport costs may also be stated, thereby increasing performance. In addition, access to new resources, expertise and foreign partners, but also the potential to expand as an entity, are vital factors for internationalisation (Hitt et al., 2006). If a company's clients or rivals are geographically diverse, a motive for internationalisation is often (Hitt et al., 2006). This might be a pull-factor that pushes businesses to internationalise themselves in a way to remain competitive. The analysis carried out on the reasons for internationalisation clearly shows that while it can be a dangerous undertaking to develop international operations (Hitt et al., 2006), it can be important for businesses to function in international markets. It will have significant consequences for their ability 
to remain competitive if they cannot follow globally varied consumers or lack access to valuable foreign services.

There is a range of literature into how internationalisation should be done, in addition to the issue of whether businesses internationalise. A differentiation may usually be made between modes of high and low authority (Anderson \& Gatignon, 1986). They also state that there is a tradeoff between the degree of control and the contribution to the resource and the danger of the entry mode with that. Export is the first one to note, starting with low control modes. This may arise directly or indirectly and is represented by a business that exports its goods abroad. Medium control modes require, for example, the formation of joint ventures. Finally, high-control modes run by foreign direct investment (FDI) are, for example, the development of a wholly-owned corporation. Having just touched on the surface of the internationalisation study carried out, it becomes clear how many things have been taken into account in previous studies. To avoid being applicable to any organisation, a description that leaves some flexibility to choose suitable companies, but is also not too broad, must be found. Therefore, this paper describes international operations as an undertaking at the firm level that crosses international boundaries.

This refers to the concept of Rugman and Verbeke (2001), which describes a multinational company as a business operating in more than one country with value-adding activities. Finally, and that goes along with the emphasis on diverse skills, it is possible to take a resource-based viewpoint on internationalisation. In general, the resource-based view deals from a market viewpoint as a set of usable capital. This view has made its way into internationalisation studies as well. The internationalisation behaviour is substantially influenced by more financial capital, dense networks and management know-how, while the most critical internationalisation strengths are high innovativeness and international orientation. The role of dynamic atributes has become increasingly significant in research on internationalisation recently.

Since internationalisation is very labour-consuming, larger family companies inherently have an edge because of their proximity to the capital (Rugman \& Verbeke, 2001). The plethora of studies showing the internationalisation of family businesses indicates that many studies have been conducted on governance and ownership problems and their consequences for the degree of diversification or entry style option (Chirico \& Nordqvist, 2010). The speed of internationalisation of family businesses and the multiple routes were also observed. Contrary, limited attention has been given to strategic aspects of family firm internationalisation (Rugman \& Verbeke, 2001), thus calling for papers that extend strategy theories to the topic.

The fundamental rationale of the theory, beginning with the agency theory, is about the interactions between agents. Two parties who demonstrate self-interest are related in these relationships through the delegation of decision-making from one to another. Risks emerge from the circumstance for the agents that lead them to obtain extra rewards, cause a conflict of interest and establish asymmetries of intelligence (Schulze et al., 2001). These disputes exist primarily between business owners and management and can thus produce risks in family businesses as well.

Research commonly notes that the key feature of agency theory on conflict of interest is excluded in organisations that are family-owned as well as controlled (Avrichir et al., 2016). Problems can exist, though, because the SEW can steer owners into risk adversity and maintain the status quo, likely leading to actions that prohibit the organisation from improving (Avrichir et al., 2016). The use of non-family managers may minimise this risk adversity, but here the classical agency issues will emerge again, because the manager can, for example, be more focused on the advancement of his or her career (Avrichir et al., 2016). In addition, family 
companies follow suboptimal systems of governance that enable the owner to benefit from the company's management. This adds to a negative link between the management of family companies and internationalisation. Analysis on the internationalisation of family firms from an agency viewpoint notes that, relative to non-family firms, family firms diversify less domestically and globally and prefer to select a culturally similar market (Gomez-Meija et al., 2010). Such effects may be attributed to the risk adversity of family companies, as Gomez-Meija et al. (2010) also found that as the market risk also rises, the ability to diversify increases. Owing to the scarcity of SEW, the ability to take risks is stronger in non-family businesses and hence contributes to further diversification attempts (Gomez-Meija et al., 2010).

Fernandez and Nieto (2005) suggest that resources can be used as the basis for internationalisation, moving on to the issue of internationalisation of family enterprises through the resource-based prism, while Graves and Thomas (2006) note that the mere existence of resources is not adequate for a competitive advantage, but must also be effectively controlled. Relationships and networks are the tools that can offer family businesses a strategic advantage in operating globally (Graves \& Thomas, 2006), but also physical and natural resources, knowledge-based resources that can, for example, emerge from a driven and well-educated young generation in the business.

Knowledge management and dynamic capabilities are also a subject that has made its way into the family business literature but has rarely been used (Barros et al., 2016). They become essential due to the particular skills family firms possess and thus make an appraisal from a family company viewpoint valid. The relationship between the organisation, the family and individual members of the family is the result of these specific capabilities. For family enterprises, the primary goal is the development of trans-generational wealth that can be accomplished by creativity and aligned adaptation to environmental changes. This requires family enterprises to be more entrepreneurial to establish dynamic skills to find potential possibilities and reconfigure their capital accordingly (Chirico \& Nordqvist, 2010). Family companies need reform in order to incorporate dynamic skills efficiently, which is frequently met with opposition because of paternalism and practices. This trend towards paternalism contributes to inertia and thus makes it impossible to establish diverse skills (Chirico \& Nordqvist, 2010). Chirico and Nordqvist (2010) propose an entrepreneurial orientation that encourages diverse skills to break down these patterns and thus implement change, creativity and, subsequently, trans-generational value development. In addition to an entrepreneurial orientation, Chirico and Nordqvist (2010) also note the role of family business leadership.

An important aspect of the family business understanding consists in the analysis of the organizational knowledge dynamics (Bratianu et al., 2011) based on the theory of knowledge fields the organizational learning (Bratianu et al., 2020; Bratianu et al., 2021).

The micro-foundations of sensing, in the sense of internationalisation, involve the activity of an organisation is seeking new opportunities in foreign markets. The willingness to search markets is one of the most critical skills for a family company to discover new opportunities. Any practice that maintains track of rivals, vendors, emerging technology or other evolving factors in the market may be market scanning and is a critical element in gaining and retaining a competitive edge (Peteraf \& Bergen, 2003). Another significant micro-foundation of sensing is the creation and maintenance of networks to explore new opportunities. In the sense of internationalisation, a network will provide the respective organisation with the requisite business awareness to minimise confusion and establish and successful market entry strategy. Chua et al. (2012), who understand the advanced access to information from a family-built network and the 
growth of the long-term family company CEO's deep tacit expertise, accept this claim. When emerging prospects are felt in a foreign setting, they need to be seized by family businesses to take advantage of their advantages. The decision of whether or not to engage in a new market depends heavily on past perceived prospects and also on the understanding of the success rate. The speed of execution is critical in the seizure process, as hypercompetitive only requires fast response times. Therefore, the opportunity to make fast and successful decisions is necessary and one of the benefits of the family business.

Organisational learning and knowledge management are one way to ensure a constant reconfiguration of capital. A theory that aims to understand the impact of learning processes on complex skills has been developed by Zollo and Winter (2002). They continue by stressing the phase of accumulation of knowledge. Information is gained in this phase by a learning process. Via knowledge articulation, this pure knowledge is later interpreted and learned. In the last step, by newly established routines, information codification, knowledge is extracted and taken back into the organisation (Zollo \& Winter, 2002). This definition should be applied in the internationalisation process to benefit about progress and disappointment while spreading to new markets. The learning and knowledge gathered continuously alters the resource base in order to cope with potential environmental changes. For family companies, learning and knowledge skills should be highly important when they have the benefit of excellent corporate culture and high employee involvement. The long-term orientation and strengthened dedication of the staff of the family sector to the company result in a low rate of fluctuation of family firms. In organisations with little change in staff, learning and information skills are more comfortable to develop as they grow in a long process.

\section{Methodology}

A relativist ontology as defined by Easterby-Smith et al. (2015) is chosen as the relevant point of view since the purpose of this analysis is to study the complex capacities of family companies with regard to internationalisation. Constructionism, in short, regards this fact as collectively created (Easterby-Smith et al., 2015). The solution from a constructionist position is also viewed in terms of the epistemological position. The analysis consequences are that the goal is to establish an interpretation of the situation by gathering rich data and generalising it by theoretical abstraction (Easterby-Smith et al., 2015). In addition, it can be argued that no hypothesis can be tested due to the lack of studies on complex capabilities of family business internationalisation, and thus the purpose of the analysis is to expand the theory, again connecting it to a relativistic and constructivist point of view (Easterby-Smith et al., 2015).

It is strongly dependent on the goal of the analysis and the expected contribution to determine whether to use a quantitative or qualitative test mode. The methodological position is also significant because constructivist methods are related to qualitative analysis, as argued by Easterby-Smith et al. (2015). In addition, it is planned to take advantage of the rich, real-world perspectives that qualitative analysis has to bring because of the research intent and the fact that the subject was previously unexplored. Qualitative analysis is an optimal starting point, as the aim is to explore trends within organisations and particular processes and skills.

An abductive methodology is picked, as opposed to inductive or deductive, to differentiate between the types of reasoning. Abduction inferences are not seen as likely or probable, but rather as plausible. In this way, an abductive approach encourages the observational evidence to be viewed in the sense of the hypothesis, but even above that and, thus, to discover more than initially imagined. 
After selecting a case approach as the key analysis technique, it is important to demonstrate various possibilities within the case study strategy. In general, a single case study can be differentiated from several case studies (Easterby-Smith et al., 2015). The most significant aspect here is the replication rationale, beginning with the virtues of a multiple case study (Eisenhardt, 1989). In case studies, a more positivist epistemology is introduced with a replication rationale and the case analysis, while used in a qualitative environment, aims at hypothesis checking (Easterby Smith et al., 2015) or theory building (Eisenhardt \& Graebner, 2007). A single case analysis, on the other hand, gives profound observations into an organisation of unique or serious characteristics and can thus explain a phenomenon in great detail (Eisenhardt $\&$ Graebner, 2007). Therefore, in order to provide deep insight into workplace environments and routines, a single case study has been presented.

The gathering of primary data in qualitative analysis can take place in a number of ways, such as using textual data such as diary techniques or a variety of qualitative interview approaches (Easterby-Smith et al., 2015). The idea that all of the possibilities have both benefits and drawbacks helps one to consider very carefully the approach choosen. As a result, interviews with employees and family members of the chosen organisation will be held for the purpose of this article presented in Table 1. As Eisenhardt and Graebner (2007) note, for case studies observing strategic trends in organisations, in-depth qualitative interviews are necessary.

Table 1. Interviewees details

\begin{tabular}{|l|l|l|l|}
\hline \multicolumn{1}{|c|}{ Subject } & \multicolumn{1}{|c|}{ Position } & \multicolumn{1}{c|}{ Type } & \multicolumn{1}{c|}{ Length } \\
\hline FBM1 & CFO & Online Call & $38 \mathrm{~min}$ \\
\hline FBM2 & Sales Manager & Online Call & $29 \mathrm{~min}$ \\
\hline FBM3 & Plant Director & Online Call & $45 \mathrm{~min}$ \\
\hline
\end{tabular}

Source: Authors' own research.

With qualitative evidence, although defined as an inductive approach, case analysis requires open coding, category formation and abstraction. Nevertheless, in their study, Dubois and Gadde (2002) explain that abductive methods can also be paired with case analysis. Therefore, the mechanism by which the data is evaluated begins with an open encoding, where the data is handled by assigning headlines and keywords.

In reality, the researched company is a consortium of seven companies of varying sizes, all operating in the manufacture and distribution of furniture. Both seven companies have 100\% Romanian owners and are entirely owned by members of the researched company family, and their operations range from logging to the manufacture of furniture and the development of websites for online commerce. The researched company group has not advertised to draw new clients in its 30- year existence but has focused on its strengths. Paradoxically, globally, the world of luxury furniture is very limited, and the manufacturers that can achieve a certain quality standard are well known. The researched company factory currently covers an area of 7 hectares and is one of the newest, non-polluting and energy-self-sustaining factories in the world. The timber used comes primarily from sources from the FSC (Forest Stewardship Council) and is harvested with respect to nature.

DOI: 10.2478/picbe-2021-0016, pp. 160-169, ISSN 2558-9652 |

Proceedings of the $15^{\text {th }}$ International Conference on Business Excellence 2021 
As for the researched company, it all began with a small workshop, and today it is a 120person production facility. The owner stated that it is actually an interconnected network of companies that offers all production processes, ranging from log handling, furniture manufacturing to $\mathrm{B} 2 \mathrm{~B}$ distribution, online shop sales and app creation. The family members agreed in 2013 to establish their own brand globally, following several years in which the business manufactured furniture for top brands.

\section{Results and discussions}

The aim of this paper was to examine, through the theoretical lens of dynamic abilities, the internationalisation of family businesses. An analysis of the existing state of the literature on internationalisation and family businesses has been carried out on this basis. In the field of family business internationalisation, numerous principles such as agency theory and stewardship theory have been explored in the current literature, but research on complex capacities in this context is underdeveloped. Therefore, it was important to establish a defined system to create a structure. In its sensing, seizing and transforming capacities, the structure meets the micro-foundations of complex capabilities. The study shows that the internationalisation of family companies can be influenced by many dynamic capabilities. Two capabilities in the sensing group, namely network capabilities and business scanning capabilities, have been established. By seeking fresh opportunities in global markets, they promote the internationalisation process. Under the seizing group, decision-making skills and managerial capabilities support family companies to take the best actions at the right time and take advantage of the newly discovered opportunities. The transformation of skills promotes the constant reconfiguration of capital in order to enhance systems and frameworks in the current international environment. Entrepreneurial skills and knowledge capabilities are the established capabilities for this group. These skills may not seem to be unique to family businesses, but it have been able to distinguish a variety of cases where the distinguishing aspects of family businesses have an impact on the creation of these capabilities. In particular, long-term orientation, workforce participation, and family culture appear to have a positive effect on the growth of dynamic skills and thus justify the role of the family in the process of internationalisation.

Research generally notes that tasks such as scanning, studying, and interpreting are critical in sensing. R\&D is also seen as a core component of complex potential (Teece, 2007). Processes that make that form of behaviour were found in the empirical evidence. The integration of sensing and non-hierarchical organisations promotes the resilience of organisations (Teece, 2007). That goes along with the analytical results that state that the operational directions in the companies studied are much more informal.

On the other hand, Teece (2007) defines network capabilities as the use of the context of the system for analytical purposes. He further names the company's climate the industry ecosystem. Scientific literature notes that local and regional networks are more entrenched in family businesses (Avrichir et al., 2016), making it impossible for them to obtain access to foreign networks. They may have more robust international networks in the case of the examined organisation, but they both understood the significance of the two networks to the performance of their international operations.

The elements of agency theory did not visibly affect the managers in their judgments on diversification. On the one side, both of them recognised the difficulties that internationalisation carries with it. Here, another viewpoint on family business management, including the 
philosophy of stewardship, can be quoted. The executives appeared to associate closely with the venture and thus placed considerable focus on the company's long-term performance.

In the theory of family businesses and dynamic capacities, entrepreneurial skills are highly prevalent. Family businesses need to cultivate an entrepreneurial mindset towards transition, according to Chirico and Nordqvist (2010) who claim that an entrepreneurial culture is essential to remaining competitive and that dynamic skills are embedded in the family business culture. As a very significant factor, culture was listed, but not as one that was consciously altered with the growth of foreign operations.

The relevance of family business features in the process of internationalisation is another implication taken from the study. The family ethos should be adopted by family businesses and used to their benefit. They will benefit from the use of employee participation in family companies as a way of network building and knowledge transfer skills. However, it can become a crucial element in the creation of transforming capacities, especially by using family culture to influence the corporate culture effectively and therefore, internal processes and frameworks.

As the international growth of a family business involves processes of transition and risk taking, family business managers are encouraged to be open to change and build an entrepreneurial culture. With little appetite for some sort of transition, family companies are also viewed as risk averse. Managers need to welcome change in order to take advantage of internationalisation truly.

\section{References}

Anderson, E., \& Gatignon, H. (1986). Modes of foreign entry: A transaction cost analysis and propositions, Journal of International Business Studies, 1-26.

Avrichir, I., Meneses, R., \& dos Santos, A. A. (2016). Do family-managed and non-family managed firms internationalize differently?, Journal of Family Business Management, 330-349.

Barros, I., Hernangómez, J., \& Martin-Cruz, N. (2016). A theoretical model of strategic management of family firms. A dynamic capabilities approach, Journal of Family Business Strategy, 149-159.

Bratianu, C., Agapie, A., \& Orzea, I. (2011). Knowledge dynamics modelling using Analytic Hierarchy Process (AHP). In Turner, G., \& Minnone, C. (Eds.), Proceedings of the $3^{\text {rd }}$ European Conference on Intellectual Capital, 18-19 April 2011, University of Nicosia, Cyprus. Reading: Academic Conferences and Publishing International, 94-102.

Bratianu, C., Prelipcean, G., \& Bejinaru, R. (2020). Exploring the latent variables which support SMEs to become learning organizations, Management \& Marketing, Challenges for the Knowledge Society, 15(2), 154-171, DOI: 10.2478/mmcks-2020-0010.

Bratianu, C., Vatamanescu, E.M., Anagnoste, S., \& Dominici, G. (2020). Untangling knowledge fields and knowledge dynamics within the decision-making process. Management Decision, 59(2), 306-323, DOI: 10.1108/MD-05-2019-0559.

Chirico, F., \& Nordqvist, M. (2010). Dynamic capabilities and trans-generational value creation in family firms: The role of organizational culture, International Small Business Journal, 487-504.

Chua, J. H., Chrisman, J. J., \& Sharma, P. (1999). Defining the family business by behavior, Entrepreneurship Theory \& Practice, 23(4).

Chua, J., Chrisman, J., Steier, L., \& Rau, S. (2012). Sources of Heterogeneity in Family Firms: An Introduction, Entrepreneurship Theory and Practice, 36(6), 1103-1113. 
De Massis, A., Frattini, F., Majocchi, A. \& Piscitello, L. (2017). Family firms in the global economy: Toward a deeper understanding of internationalization determinants, processes, and outcomes, Global Strategy Journal, 8(1).

D'Souza, D., \& McDougall, P. (1989). Third World Joint Venturing: A Strategic Option for the Smaller Firm, Entrepreneurship Theory and Practice, 13(4).

Dubois, A., \& Gadde, L.-E. (2002). Systematic combining: an abductive approach to case research, Journal of business research, 553-560.

Easterby-Smith, M., Thorpe, R., \& Jackson, P. R. (2015). Management \& Business Research. $5^{\text {th }}$ Edition ed. s.1.:SAGE Publications Ltd.

Eisenhardt, K. M., \& Graebner, M. E. (2007). Theory building from cases: Opportunities and challenges, Academy of Management Journal, 25-32.

Fernádez-Aráoz, C. (2015). Leadership Lessons from Great Family Businesses, Harvard Business Review.

Fernandez, Z., \& Nieto, M. J. (2005). Internationalization Strategy of Small and Medium Sized Family Businesses: Some Influential Factors, Family Business Review, 77-89.

Gómez-Mejía, L. R. et al. (2007). Socioemotional wealth and business risks in family controlled firms: Evidence from Spanish olive oil mills, Administrative science quarterly, 106-137.

Graves, C., \& Thomas, J. (2006). Internationalization of Australian family businesses: A managerial capabilities perspective, Family Business Review, 207-224.

Hitt, M. A., Tihanyi, L., Miller, T., \& Connelly, B. (2006). International diversification: Antecedents, outcomes, and moderators, Journal of Management, 831-867.

Hoy, F., \& Sharma, P. (2009). Entrepreneurial Family Firms. Upper Saddle River, NJ, Prentice Hall.

Johanson, J., \& Mattsson, L.-G. (1988). Internationalization in industrial systems internationalization - a network approach. In: N. Hood \& J. Vahlne, eds. Strategies in Global Competition, Chichester and New York, John Wiley, 287-314.

Johanson, J., \& Vahlne, J.-E. (1977). The internationalization process of the firm - a model of knowledge development and increasing foreign market commitments, Journal of international business studies, 23-32.

Johanson, J., \& Wiedersheim-Paul, F. (1975). The internationalization of the firm - four swedish cases, Journal of management studies, 305-323.

Jones, M. V., \& Coviello, N. E., 2005. Internationalisation: conceptualising an entrepreneurial process of behaviour in time, Journal of international business studies, 284-303.

Knight, G. A., \& Liesch, P. W. (2016). Internationalization: From incremental to born global, Journal of World Business, 93-102.

Oesterle, M.-J., Richta, H. N., \& Fisch, J. H. (2013). The influence of ownership structure on internationalization, International Business Review, 187-201.

Peteraf, M., \& Bergen, M. (2003). Scanning dynamic competitive landscapes: a market-based and resource-based framework, Strategic Management Journal, 24(10), 1027-1041.

Rugman, A. M., \& Verbeke, A. (2001). Subsidiary-specific advantages in multinational enterprises, Strategic Management Journal, 237-250.

Schulze, W. S., Lubatkin, M. H., Dino, R. N., \& Buchholtz, A. K. (2001). Agency relationships in family firms: Theory and evidence, Organization Science, 99-116.

Singh, N., Bartikowski, B., Dwivedi, Y., \& Williams, M. (2009). Global megatrends and the web: convergence of globalization, networks and innovation, ACM SIGMIS Database, 40(4). 
Teece, D. (2007). Explicating dynamic capabilities: the nature and microfoundations of (sustainable) enterprise performance, Strategic Managament Journal, 28(13), 1319-1350.

Teece, D., Pisano, G., \& Shuen, A. (1997). Dynamic Capabilities and Strategic Management, Strategic Management Journal, Vol. 18, 509-533.

Zollo, M., \& Winter, S. (2002). Deliberate Learning and the Evolution of Dynamic Capabilities, Organization Science, 13(3), 339-351. 